\title{
Anesthetic considerations on pulmonary hypertension: A case report and minireview
}

\author{
Andi Koraqi ${ }^{1}$, Denada Lacej ${ }^{1}$, Rezart Xhani ${ }^{2}$, Myzafer Kaci ${ }^{3}$, Gjergj Andrea $^{3}$, Rudin Domi ${ }^{4}$ * \\ ${ }^{1}$ Department of Microbiology, "Mother Teresa” University Hospital Centre, Albania \\ ${ }^{2}$ Department of Surgery, Division of Urology, "Mother Teresa" University Hospital Centre, Albania \\ ${ }^{3}$ Department of Surgery, Division of General Surgery, "Mother Teresa" University Hospital Centre, Albania \\ ${ }^{4}$ Department of Surgery, Division of Anaesthesiology and Intensive Care, "Mother Teresa" University Hospital Centre, Albania
}

\section{Email address:}

rdomi73@yahoo.it (R. Domi)

\section{To cite this article:}

Andi Koraqi, Denada Lacej, Rezart Xhani, Myzafer Kaci, Gjergj Andrea, Rudin Domi. Anesthetic Considerations on Pulmonary Hypertension: A Case Report and Minireview. Clinical Medicine Research. Vol. 3, No. 6, 2014, pp. 200-202.

doi: $10.11648 /$ j.cmr.20140306.17

\begin{abstract}
Pulmonary hypertension presents a great challenge to the anesthesiologist. The number of patients suffering from pulmonary hypertension presenting for surgery is increasing because of increased age and the modern medical and surgical therapy as well. We present a case of a patient suffering from pulmonary hypertension scheduled for left radical nephrectomy due to left kidney tumor. Preoperative optimization and prevention of deterioration of pulmonary hypertension and right side heart failure are the problems the anesthesiologist must deal with. A good collaboration among cardiologist, anesthesiologist, and the surgeon can guarantee the patient's outcome.
\end{abstract}

Keywords: General Anesthesia, Pulmonary Hypertension, Right Heart Failure

\section{Introduction}

Pulmonary hypertension is a rare disease, but with increased preoperative co morbidity and mortality. $\mathrm{PH}$ is divided in the primary form and the secondary one. Primary $\mathrm{PH}$ is a rare condition without any evident causes (1), whereas the secondary $\mathrm{PH}$ is often due to cardiac and/or pulmonary diseases. Chronic pulmonary diseases, mitral valve stenosis/regurgitation, and left side ventricular diseases, are the commonest causes of secondary $\mathrm{PH}$. The pathophysiological mechanisms include hypoxia-induced vasoconstriction (2), elevated left atrial pressure, and increased pulmonary venous and arterial pressure. PH can progress in atrial fibrillation, and right side heart failure with tricuspid valve regurgitation, further increasing the gravity of the disease (3). The anesthesiologist's role consists on preoperative optimization, prevention of further deterioration of $\mathrm{PH}$, and finally prevention or treatment of acute right side heart failure.

\section{Case Report}

The patient V.B, number 550754, 72 years old white man, with no previous cardiac medical history, was recovered in our institute diagnosed with left kidney tumor. In the preoperative consult, unexpected atrial fibrillation was clinically diagnosed confirmed by ECG as well. Echocardiography examination found aortic valve stenosis 1 , $7 \mathrm{~cm} 2$, moderate mitral valve regurgitation (40-60\% regurgitation fraction), left ventricle and left atrium dilatation with normal function (EF 61\%, SHF 33\%), tricuspid valve regurgitation, and systolic pulmonary hypertension (PsAP 52 $\mathrm{mmHg}$ ). Thoracic X-Ray examination revealed cardiomegaly and a decreased cardiopulmonary ratio. Blood gases and the other biochemistry examination were within normal limits. Atenolol, digoksine, captopril, nitrates, forusemid, and LWMH, were administered at least one week before surgery. The patient was premedicated with oral Diazepam $10 \mathrm{mg}$ the night before the surgery, and morfine sulfate $10 \mathrm{mg}$ intramuscularly 30 minutes before the induction of anesthesia. In operating room after peripheral venous cannula was inserted, right radial artery and right internal jugular vein were cannulated with a $20 \mathrm{G}$ arterial cannula and $7.5 \mathrm{~F}$ central venous catheter. A fast track anesthesia was made (Fentanyl 5 $\mathrm{mcg} / \mathrm{kg}$, Propofol $2 \mathrm{mg} / \mathrm{kg}$, cis-atracurium $0.15 \mathrm{mg} / \mathrm{kg}$ ). Monitoring included invasive arterial monitoring, central venous pressure, ECG, temperature, urine output, and end- 
Tidal carbon dioxide. The anesthesia was maintained with sevoflurane, profofol infusion, fentanyl and cis-Atracurium as needed. Priority was given to pulmonary hypertension, mitral regurgitation and possibly right cardiac failure. There was performed mild hyperventilation, infusion of millrinon and adrenaline, small bolus doses of phenilephrine and nitroglycerine. The patient was discharged uneventful on 8-th postoperative day, being advised for surgical correction of mitral and aortic valve diseases.

\section{Discussion}

\subsection{Preoperative Optimization}

The pulmonary artery pressures vary from $18-25 \mathrm{mmHg}$ (systolic) and 6-10 mmHg (diastolic). The pressure over 25 $\mathrm{mmHg}$ at rest or more than $30 \mathrm{mmHg}$ with exercise is considered to be $\mathrm{PH}$. PH can be usually presented with difficulties in breathing, weakness, fatigue, and rhythm disturbances. Chest X-ray shows prominent pulmonary artery, whereas ECG (4) presents right axis deviation. Pulmonary function test can reveal the respiratory origin of $\mathrm{PH}$. Echocardiography $(5,6)$ may be helpful in determination of valve malfunctions, right atrial enlargement, elevated pulmonary pressure, and tricuspid regurgitation. The pathophysiology (4-6) changes are complex. Right ventricle ejects in pulmonary bed which is characterized by one tenth of systemic pressure. The pulmonary vasoconstriction can increase right ventricle pressure and decreases left ventricular filling resulting in low cardiac output. The increasing right ventricle afterload can precipitate ventricular failure. Right ventricle enlargement results in annular dilatation of tricuspid valve and tricuspid regurgitation. Tricuspid regurgitation can further increase right ventricle wall stress, resulting in myocardial ischemia and infarction. General therapy's goals are correction/prevention of hypoxia, hypercapnia, and acidosis. Maintaining right ventricular function by increasing its inotropism and by decreasing afterload is the principal goal of the anesthetic practice. Digoxine, calcium channel blockers, diuretics, and low molecular weight heparin are the commonest used drugs in the preoperative period.

\subsection{Anesthetic Care}

After preoperative evaluation and preparation, the patient is scheduled for surgery. Arterial line, central line, pulmonary artery catheter, and occasionally transesophageal echocardiography are mandatory. Besides of anesthetic technique (general or regional anesthesia), ensuring oxygenation and ventilation remain the principal goals. The anesthesiologist must beware of negative effects of inhalator drugs on cardiovascular system. Using large opioid doses can minimize volatile anesthetics. All the situations that can increase right ventricle afterload must be avoided. Prophylactic low dose of dobutamine or millrinon combined or/not with norarenaline may be helpful. The anesthesiologist must avoid hypoxemia, hypercarbia, acidosis, hypovolemia, and increasing afterload of right ventricle. Adequate anesthesia's depth must be ensured. Table 1 summarizes the drugs usually helpful for PH.

Table 1. The common drugs used for $\mathrm{PH}$.

\begin{tabular}{ll}
\hline Drug & Dose \\
\hline Dobutamine & $5-10 \mathrm{mcg} / \mathrm{kg} /$ minute \\
Millrinone & $50 \mathrm{mcg} / \mathrm{kg}$ bolus, $075 \mathrm{mcg} / \mathrm{kg} / \mathrm{min}$ infusion \\
Dopamine & $5-10 \mathrm{mcg} / \mathrm{kg} / \mathrm{minute}$ \\
Adrenaline & $2-20 \mathrm{mcg} / \mathrm{minute}$ \\
Noradrenaline & $2-20 \mathrm{mcg} /$ minute \\
NO & $20-40 \mathrm{ppm}$ \\
Prostacicline & $4-10 \mathrm{ng} / \mathrm{kg}$ \\
\hline
\end{tabular}

\section{Medical Therapy}

Medical treatment includes intravenous and volatile vasodilator drugs. Intravenous vasodilators are milrinone, dobutamine, dipiradamole, calcium channel blockers, and nitroglycerine. Volatile drugs include prostaglandins (prostacycline, epoprostenol, treprostinil, iloprost), and nitric oxide. Oral pulmonary vasodilators are presented by endotheline receptors antagonists (bosentan), and Viagra (sildenafil). Milrinone reduces systemic and pulmonary pressure, while increasing right ventricle inotropism. Exaggerated systemic hypotension presents an eminent risk for further deterioration of right ventricle function and ischemia. The combination of milrinone and vasopressors as noradrenaline or phenilephrine, can minimize this side effect (7). Calcium channel blockers reduces right ventricle afterload by smooth musculature releasing. Nitric oxide produces pulmonary vasodilatation without systemic hypotension through cyclic guanosine monophosphate (8). Prostacycline is available in both forms: inhaled and intravenous. Prostacycline and other prostaglandins (9) decrease pulmonary pressure, right atrial pressure. It is recently reported that combination with nitric oxide is more effective than alone therapy (10). Levosimendan is a new inotropic drug, increasing inotropism of right ventricle mediated induced calcium sensitized cells activation.

The principal anesthetic care issues (11) remain reducing right ventricle afterload (vasodilators, deep anesthesia), maintaining its inotropism (inotropes and regional anesthesia if available), and avoiding all deteriorating situations (hypoxia, hypercapnia, acidosis, light general anesthesia).

\section{Conclusions}

Several problems are faced by anesthesiologist managing a patient suffering from $\mathrm{PH}$ undergoing to non cardiac surgery. Prevention of exacerbation of $\mathrm{PH}$, and right heart failure are the crucial steps that can improve the patient's outcome.

\section{References}

[1] Loyd J, Butler M, Foround T, et al. Genetic anticipation and abnormal gender ratio at birth in familial primary pulmonary hypertension. Am J Respir Crit Care Med 1995; 152:93-97. 
[2] Fox Ch, Kalarickal Ph, Yarboruough M, Jin J. Perioperative management including new pharmacological vistas for patients with pulmonary hypertension for non cardiac surgery. Curr Opin Anaesthesiol 2008; 21:467-472.

[3] Gaine S. Pulmonary hypertension. JAMA 2000; 284: 31603168.

[4] Blaise G, Langleben D, Hubert B. Pulmonary artery hypertension: pathophysiology and anesthetic approach. Anesthesiology 2003; 99:1415-1432.

[5] Bossone E, Paciaccio G, Larussi D et al. The prognostic role of the ECG in primary pulmonary hypertension. Chest 2002; 121:513-518.

[6] Nauser T, Stives S. Diagnosis and treatment of pulmonary hypertension. Ann Fam Phys 2001; 63: 1789-1796.
[7] Tanake H, Tajimi K, Moritsune O, et al. Effects of lirinone on pulmonary vasculature in normal dogs and dogs with pulmonary hypertension. Crit Care Med 1991; 19:68-74.

[8] Ichinose F, Roberts J, Zapol W. Inhaled nitric oxide: a selective pulmonary vasodilator-current uses and therapeutic potential. Circulation 2004; 109: 3106-3111.

[9] Cabrol S, Sousa S, Jaix X, et al. Intravenous epoprostenol in inoperable chronic thromboembolic pulmonary hypertension. J Heart Lung Transplant 2007; 26:357-362.

[10] Wilkens H, Guth A, Konig J, et al. Effect of iloprost plus oral sildenafil in patient with primary pulmonary hypertension. Circulation 2001; 104:1218-1222.

[11] Gordon C, Colard Ch, Pan W. Intraoperative management of pulmonary hypertension and associated right heart failure. Curr Opin Anaesthesiol 2010; 23: 49-56. 